\title{
Severe hypercarbia during kneeling-prone retroperitoneoscopic adrenalectomy
}

\section{G.J.Mar*\#, M.Ferguson*}

*Department of Anaesthesia, Box Hill Hospital, Eastern Health, Victoria, Australia

\#School of Medicine, Monash University

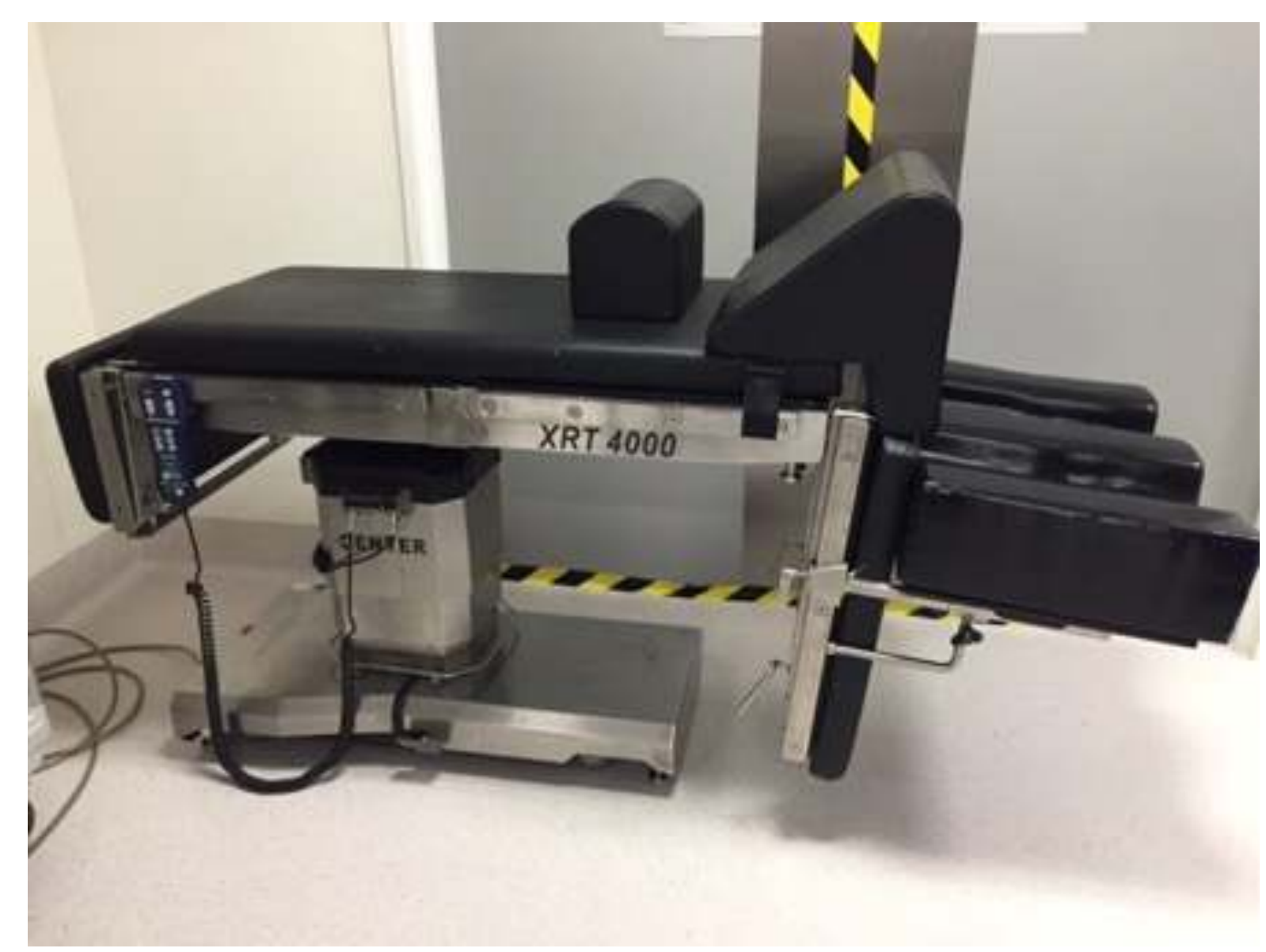

\section{Background:}

Surgical methods are constantly evolving towards improved minimally invasive approaches, with the aims of reduced postoperative morbidity and earlier return to premorbid functional status.

The retroperitoneoscopic adrenalectomy in the kneeling-prone position is an example which presents new challenges for the anaesthetist.

\section{Case Report:}

We report the case of a 61-year old, ASA II patient with well controlled asthma and a 20 pack year smoking history, who developed severe hypercarbia $(\mathrm{PaCO} 2>150 \mathrm{mmHg})$ and respiratory acidosis $(\mathrm{pH}$ 6.94) during elective posterior retroperitoneoscopic adrenalectomy for an adrenal adenoma.

This was performed in a kneeling-prone position. Respiratory parameters improved only after expedited surgical completion and supine repositioning.

Possible causes included carbon dioxide $\left(\mathrm{CO}_{2}\right)$ absorption via subcutaneous emphysema, higher insufflation pressures required for retroperitoneoscopic access, and the kneelingprone position.

Retroperitoneoscopic surgery is associated with increased $\mathrm{CO}_{2}$ absorption compared to laparoscopy, and the anaesthetist should monitor $\mathrm{CO}_{2}$ levels with vigilance.

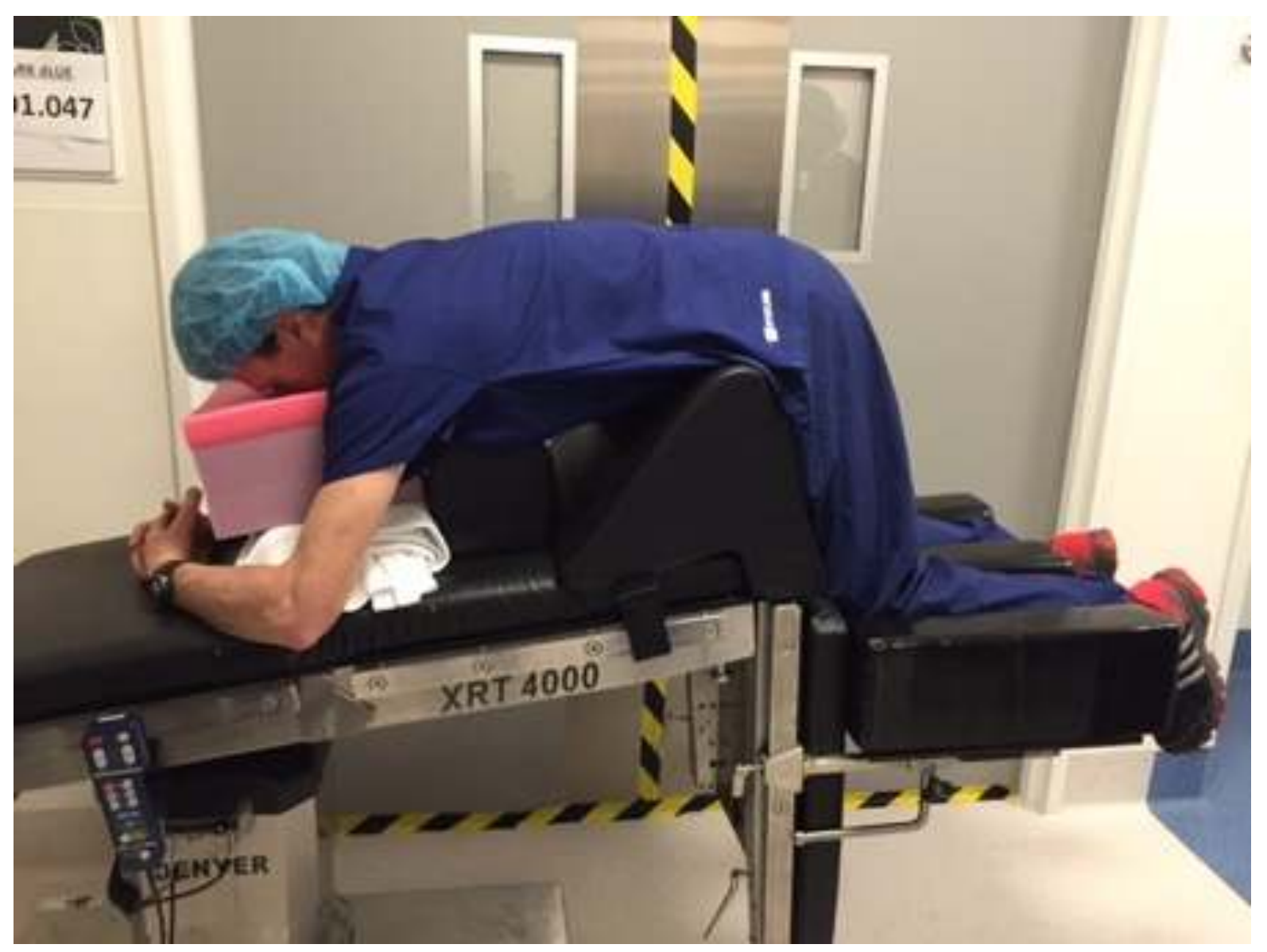

\section{Discussion}

Minimally invasive adrenalectomy can be performed via laparoscopic transperitoneal, lateral retroperitoneal, and posterior retroperitoneal approaches.

The posterior retroperitoneal approach for adrenalectomy has a number of potential advantages, including reduced pain and reduced length of hospital stay.

Anaesthetic challenges specific to the posterior retroperitoneal approach include kneeling prone patient positioning, and management of potentially high retroperitoneal carbon dioxide insufflation pressures. This is the first reported case of massive hypercarbia associated with retroperinoeoscopic adrenalectomy.

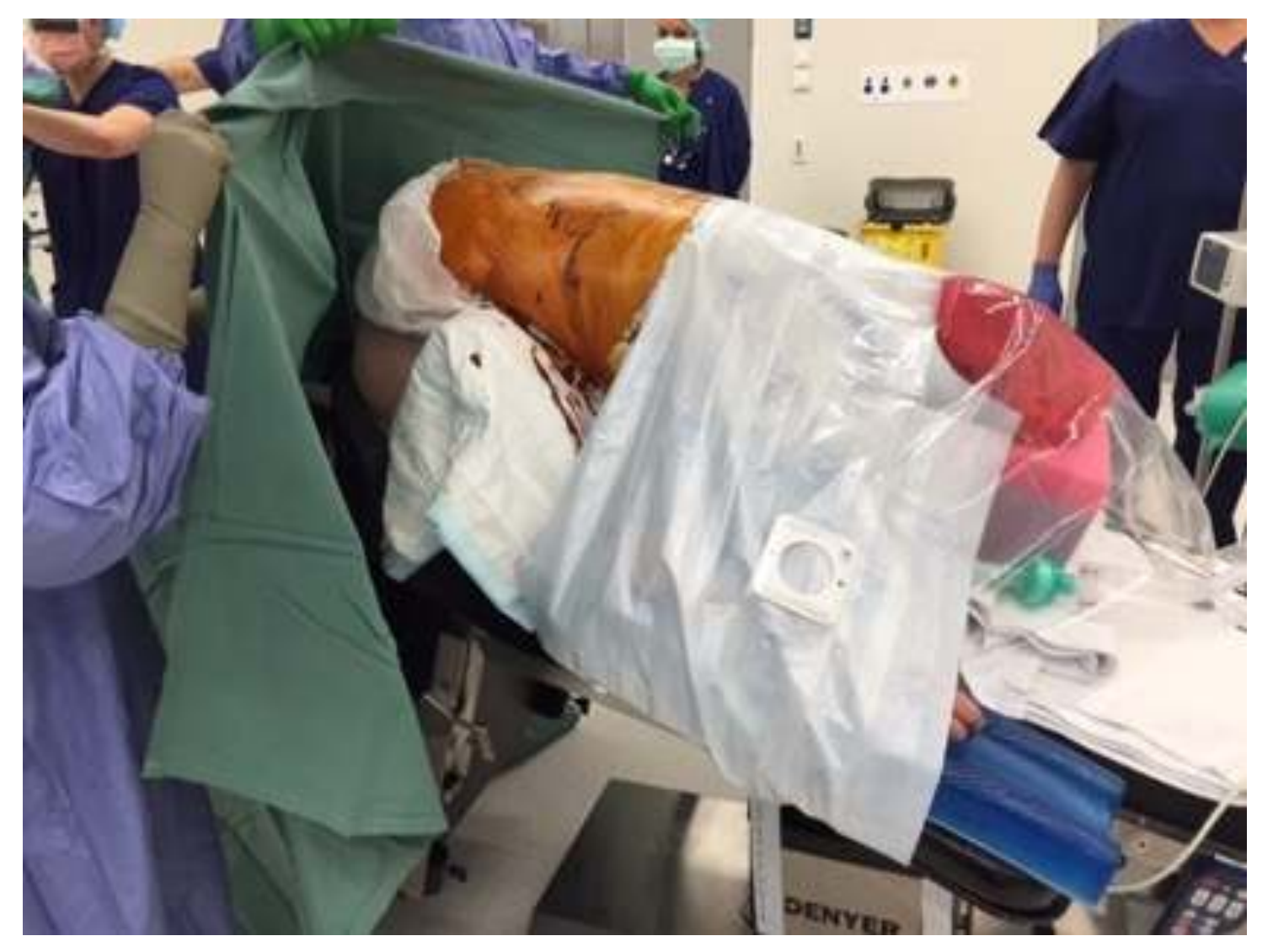

\section{Learning points:}

Kneeling prone position for retroperitoneoscopic adrenalectomy has many advantages including less pain and faster return to premorbid function. One should remain mindful of the potential for severe hypercarbia with this technique which may require early termination of the procedure. 